\title{
PERBANDINGAN PERHITUNGAN HARGA POKOK PRODUKSI METODE TRADISIONAL DENGAN METODE ACTIVITY BASED COSTING (ABC) SYSTEM PADA UD. MITRA UTAMA
}

\section{The Comparison of Cost of Goods Sold (HPP) Calculation Using Traditional and Activity Based Costing Method in UD. Mitra Utama}

\author{
Surya Yulyanto ${ }^{1}$; Ahmad Jibrail ${ }^{1}$; Fitriah Permatacita ${ }^{2}$ \\ ${ }^{1}$ Program Studi Akuntansi, Fakultas Ekonomi dan Bisnis Universitas Teknologi Sumbawa
}

${ }^{2}$ Program Studi Ekonomi Pembangunan, Fakultas Ekonomi dan Bisnis Universitas Teknologi Sumbawa

*)E-mail : Suryayulyanto017@gmail.com

\begin{abstract}
Cost of Goods Sold (HPP) determination has become an important thing to be solved by Small and Medium Enterprises (UKM) in order to get maximum profit. This study aims to identify the current method of HPP calculation applied by UD Mitra Utama (a construction materials store) and compares it's result with the Activity Based Costing (ABC) method. This study uses descriptive method with a study case approach. The research revealed that there is a different results of HPP calculation between traditional cost accounting method and the ABC system. The HPP value of paving block product using traditional method is Rp 11,271,190, while it resulting HPP value of Rp 11,149,449 using the ABC system. In addition, the value of HPP for bricks product using the traditional method is 22,746,518, and resulting Rp 22,868,260 using the ABC system method. These differences of HPP cause overcosting or over cost loading for paving block product, and undercosting or less cost loading for bricks. Therefore, UD Mitra Utama should consider to use the ABC system rather than traditional method in its HPP calculation.
\end{abstract}

Key words: Cost of Goods sold (HPP) determination, Activity Based Costing (ABC) method

\begin{abstract}
ABSTRAK
Penentuan HPP menjadi sangat penting dilakukan oleh UKM untuk memberikan penentuan harga jual yang tepat sehingga dapat menghasilkan laba yang optimal. Penelitian ini bertujuan untuk mengetahui metode perhitungan HPP yang selama ini diterapkan oleh UD. Mitra Utama (perusahaan bahan bangunan) dan membandingkannya dengan metode Activity Based Costing (ABC) System. Penelitian ini menggunakan metode deskriptif dengan pendekatan studi kasus. Hasil penelitian menunjukkan bahwa terjadi perbedaan hasil perhitungan antara metode akuntansi biaya tradisional dengan metode Activity Based Costing (ABC). Perhitungan HPP dengan menggunakan metode akuntansi biaya tradisional menghasilkan HPP untuk paving block sebesar Rp 11,271,190, untuk batako sebesar Rp 22,746,518. Sedangkan perhitungan HPP dengan menggunakan metode Activity Based Costing (ABC) System menghasilkan HPP untuk paving block sebesar Rp11,149,449, dan untuk batako sebesar Rp22,868,260. Dari perbedaan hasil perhitungan HPP antara metode akuntansi biaya tradisional dengan metode Activity Based Costing (ABC) System mengakibatkan produk paving block mengalami overcosting atau pembebanan biaya terlalu tinggi, sedangkan produk batako mengalami undercosting atau pembebanan biaya terlalu rendah. UD. Mitra Utama diharapkan dapat mengganti metode akuntansi biaya tradisional dengan menggunakan metode Activity Based Costing $(A B C)$ dalam menentukan harga pokok produksi.
\end{abstract}

Kata kunci : Penentuan Harga Pokok Produksi, metode Activity Based Costing (ABC)

\section{Pendahuluan}

Usaha kecil dan menengah (UKM) di berbagai negara termasuk di Indonesia merupakan salah satu penggerak perekonomian rakyat yang tangguh. Hal ini karena kebanyakan para pengusaha kecil dan menengah berangkat dari industri keluarga atau rumahan. Dengan demikian konsumennya pun berasal dari kalangan menengah ke bawah. Selain itu, Peranan UKM terutama sejak krisis moneter tahun 1998 dapat dipandang sebagai katup penyelamat dalam proses pemulihan ekonomi nasional, baik dalam mendorong laju pertumbuhan ekonomi maupun penyerapan tenaga kerja (Ilham, 2013) 
Permasalahan yang muncul dalam suatu UKM adalah mengenai laporan tentang biaya yang dikeluarkan selama proses produksi dalam suatu periode. Penentuan HPP menjadi hal yang sangat penting karena dapat menjadi hal yang menentukan pendapatan para pelaku UKM karena berkaitan dengan laba yang akan diperoleh perusahaan. Komponen pembentukan laba adalah pendapatan yang diperoleh dari hasil penjualan produksi dan jasa yang dihasilkan oleh perusahaan. Sedangkan biaya adalah pengorbanan yang harus dikeluarkan oleh perusahaan untuk memproduksi atau menghasilkan suatu barang dan jasa. Biaya tersebut disebut sebagai biaya harga pokok atau harga pokok produksi (Mulyadi, 1992).

Penentuan HPP menjadi masalah yang harus dilakukan oleh UKM untuk memberikan penentuan harga jual yang tepat sehingga dapat menghasilkan laba yang optimal. Harga pokok produksi (HPP) sangat menentukan laba rugi perusahaan. Dengan demikian apabila perusahaan kurang teliti atau salah dalam penentuan harga pokok produksi, mengakibatkan kesalahan dalam menentukan laba rugi yang diperoleh perusahaan. Mengingat arti pentingnya harga pokok produksi yang memerlukan ketelitian dan ketepatan, apa lagi dalam persaingan yang tajam di industri seperti saat ini memacu perusahaan yang satu bersaing dengan perusahaan yang lain, dalam menghasilkan produk yang sejenis maupun produk substitusi (Ilham, 2013).

UD Mitra Utama merupakan perusahaan manufaktur dalam bidang conblock (paving stone), batako, beton. Perusahaan ini belokasi di Jalan Sultan Kaharuddin No. 9 Sumbawa Besar. Perusahaan ini dipilih sebagai objek penelitian karena perusahaan belum menerapkan metode akuntansi biaya dalam perhitungan harga pokok produksinya. Ini dapat dilihat dari tabel harga produksi UD. Mitra Utama di bawah ini:

Tabel 1. Harga Pokok Produksi UD. Mitra Usaha Selama Mei 2017

\begin{tabular}{|c|c|c|c|}
\hline Jenis Bahan Baku & Volume & Harga Satuan & Jumlah biaya \\
\hline Pasir & 90 & Rp 150,000 & Rp 13,500,000 \\
\hline Semen & 87 & $\mathrm{Rp} \quad 62,500$ & $\mathrm{Rp} \quad 5,437,500$ \\
\hline Kerikil & 30 & $\mathrm{Rp} \quad 50,000$ & $\mathrm{Rp} \quad 1,500,000$ \\
\hline Gajii Karyawan & & & $\mathrm{Rp} 13,200,000$ \\
\hline biaya air & & & $\mathrm{Rp} \quad 125,000$ \\
\hline $\begin{array}{l}\text { Penyusutan Alat } \\
\text { Cetak }\end{array}$ & & & $\mathrm{Rp} \quad 140,625$ \\
\hline Penyusutan gedung & & & $\mathrm{Rp} \quad 114,583$ \\
\hline
\end{tabular}

Sumber: UD Mita Usaha, 2017

Harga pokok produksi merupakan hal yang sangat penting, karena harga pokok produksi dapat dipakai dalam pengambilan keputusan yang dilakukan perusahaan. Selama ini pemilik usaha telah melakukan perhitungan atas biaya produksi, tetapi hal tersebut belum digunakan sebagai dasar penentuan HPP per/unit. Perusahaan dalam membuat laporan harga pokok produksi belum dapat menunjukan harga pokok produksi yang tepat dan benar sesuai dengan pengumpulan biaya produksinya. Dengan demikian, penelitian ini bertujuan untuk membandingkan perhitungan HPP metode tradisional yang diterapkan oleh UD Mitra Utama dengan perhitungan HPP dengan metode Activity Based Costing (ABC) System.

\section{Metode Penelitian}

Penelitian ini menggunakan bersifat deskriptif kuantitatif dengan menggunakan pendekatan studi kasus. Penelitian deskriptif menurut Wiratha (2006:154) adalah penelitian yang berkaitan dengan data yang dikoleksi untuk menceritakan sesuatu atau menegaskan suatu fenomena, gejala, dan suatu konsep juga menjawab pertanyaan-pertanyaan yang berhubungan dengan status subyek penelitian saat ini, misalnya perlakuan atau opini terhadap individu, organisasi atau sebagainya.

Data yang gunakan dalam penelitian ini bersumber dari 2 data, yaitu :

1. Data primer adalah data yang langsung dikumpulkan oleh peneliti dari sumber pertamanya yaitu wawancara dengan pemilik perusahaan (UD. Mitra Utama) atau langsung dengan bagian terkait di perusahaan.

2. Data Sekunder dalam penelitian ini diperoleh dari laporan keuangan atau catatan akuntansi perusahaan (UD. Mitra Utama).

\section{Hasil dan Pembahasan}

UD. Mitra Utama dalam bulan Mei 2017 memproduksi batako dan paving block sebanyak 25.500 unit. UD. Mitra Utama memproduksi Batako dengan ukuran 10 $\mathrm{cm}$ X $20 \mathrm{~cm} \mathrm{X} 40 \mathrm{~cm}$ dan paving block yang diproduksi UD. Mitra Utama berukuran $10 \mathrm{~cm} \mathrm{X} 10 \mathrm{~cm}$ X $21 \mathrm{~cm}$.

Dalam memproduksi paving block dan batako UD. Mitra Utama memperhitungkan volume per unit dari produk yang dihasilkan. Perhitungan UD. Mitra Utama sebagai berikut :

- $\quad$ Paving Block $=10 \mathrm{~cm} \times 20 \mathrm{~cm} \times 40 \mathrm{~cm}=$ 8.000 volume per unit

- Batako $=10 \mathrm{~cm} \times 10 \mathrm{~cm} \times 21 \mathrm{~cm}=2.100$ volume per unit

Dari 25.500 unit yang diproduksi UD. Mitra Utama 16.575 unit dalam bentuk paving block dan 8.926 unit dalam bentuk Batako. Ini dapat dilihat dari table berikut; 
Tabel 2. Persentase Produk UD. Mitra Usaha Periode Mei 2017

\begin{tabular}{ccccc}
\hline Jenis & $\begin{array}{c}\text { volume } \\
\text { per unit }\end{array}$ & $\begin{array}{c}\text { unit yang } \\
\text { diproduksi }\end{array}$ & $\begin{array}{c}\text { volume } \\
\text { yang } \\
\text { diproduksi }\end{array}$ & presentase \\
\hline Paving Block & 2,100 & 16,575 & $34,807,500$ & $67 \%$ \\
Batako & 8,000 & 8,925 & $71,400,000$ & $33 \%$ \\
\hline Total & & $\mathbf{2 5 , 5 0 0}$ & $\mathbf{1 0 6 , 2 0 7 , 5 0 0}$ & $\mathbf{1 0 0} \%$ \\
\hline Sumber: \% & & & &
\end{tabular}

Sumber : UD.Mitra Utama

\section{A. Biaya Bahan Baku}

Berikut perhitungan biaya bahan baku yang dilakukan oleh UD. Mitra utama dalam memproduksi Batako dan Paving Block:

Tabel 3. Biaya bahan baku batako dan paving block periode mei 2017

\begin{tabular}{cccc}
\hline $\begin{array}{c}\text { Jenis Bahan } \\
\text { Baku }\end{array}$ & Volume & $\begin{array}{c}\text { Harga } \\
\text { Satuan }\end{array}$ & Jumlah biaya \\
\hline Pasir & 90 & Rp. 150.000 & Rp. 13.500 .000 \\
Semen & 87 & Rp. 62.500 & Rp. 5.437 .500 \\
Kerikil & 30 & Rp. 50.000 & Rp. 1.500 .000 \\
\hline & Jumlah & Rp. 20.437.500
\end{tabular}

Dalam perhitungan biaya bahan baku Paving Block dan Batako UD. Mitra Utama membagi jumlah biaya bahan baku dengan volume produksi oleh masing-masing produk. Ini terlihat dari tabel berikut :

Tabel 4. Perhitungan biaya bahan baku paving block periode mei 2017

\begin{tabular}{ccccccc}
\hline $\begin{array}{c}\text { Jenis Bahan } \\
\text { Baku }\end{array}$ & Volume & \multicolumn{2}{c}{$\begin{array}{c}\text { Harga } \\
\text { Satuan }\end{array}$} & Jumlah biaya \\
\hline Pasir & 29,50 & $\mathrm{Rp}$ & 150.000 & $\mathrm{Rp}$ & 4.424 .370 \\
Semen & 28,51 & $\mathrm{Rp}$ & 62.500 & $\mathrm{Rp}$ & 1.782 .038 \\
Kerikil & 9,83 & $\mathrm{Rp}$ & 50.000 & $\mathrm{Rp}$ & 491.597 \\
& & & & & & \\
\hline & Jumlah & & & $\mathbf{R p}$ & $\mathbf{6 . 6 9 8 . 0 0 4}$ \\
\hline
\end{tabular}

Sumber : Data primer diolah, 2017

Dari tabel di atas perhitungan bahan baku paving block berjumlah Rp. 6.698.004. ini didapat dari membagi jumlah biaya bahan baku UD. Mitra Utama dengan volume produksi produk block UD. Mitra Utama, perhitungan bahan baku paving block sebagai berikut :

Rp.20.437.500 x 34,807,500 / 106,207,500 = Rp. 6.698 .004
Tabel 5. Perhitungan Biaya Bahan Baku Batako Periode Mei 2017

\begin{tabular}{cccrcc}
\hline $\begin{array}{c}\text { Jenis Bahan } \\
\text { Baku }\end{array}$ & Volume & \multicolumn{2}{c}{$\begin{array}{l}\text { Harga } \\
\text { Satuan }\end{array}$} & Jumlah biaya \\
\hline Pasir & 60,50 & $\mathrm{Rp}$ & 150.000 & $\mathrm{Rp}$ & 9.075 .630 \\
Semen & 58,49 & $\mathrm{Rp}$ & 62.500 & $\mathrm{Rp}$ & 3.655 .462 \\
Kerikil & 20,17 & $\mathrm{Rp}$ & 50.000 & $\mathrm{Rp}$ & 1.008 .403 \\
\hline & Jumlah & & & & Rp 13.739.496 \\
\hline
\end{tabular}

Sumber: Data primer diolah, 2017

Dari tabel di atas perhitungan bahan baku Batako berjumlah Rp.13.739.496. didapat dari membagi jumlah biaya bahan baku UD. Mitra Utama dengan volume produksi Batako UD. Mitra Utama, perhitungan biaya bahan baku Batako sebagai berikut :

Rp.20.437.500 x 71.400.000/ 106.207.500 = Rp 13.739.496

B. Biaya Tenaga Kerja Langsung

Biaya tenaga kerja langsung yang dikeluarkan Pada pembuatan Paving Block dan Batako di UD. Mitra Utama dapat dilihat pada tabel berikut:

Tabel 6. Perhitungan Biaya Tenaga Kerja Langsung UD. Mitra Utama Periode mei 2017

\begin{tabular}{ccc}
\hline Jenis & \multicolumn{2}{c}{ Jumlah Biaya } \\
\hline Gajii Karyawan Tetap & Rp & $8,100,000$ \\
Gaji Karyawan Tidak Tetap & Rp & $5,100,000$ \\
\hline Jumlah & Rp & $\mathbf{1 3 , 2 0 0 , 0 0 0}$ \\
\hline Sumber : UD. Mitra Utama & \multicolumn{2}{l}{}
\end{tabular}

Perhitungan biaya tenaga kerja langsung UD. Mitra Utama dialokasikan kepada masing-masing produk dengan membagi jumlah biaya tenaga kerja langsung UD. Mitra Utama dengan volume produksi masingmasing produk UD. Mitra Utama, perhitungan pengalokasian tenaga kerja langsung UD. Mitra Utama sebagai berikut :

- Pengalokasian BTKL paving block

Rp. 13.200.000 X 3.807.500/ 106.207.500 = Rp. 4.326.050

- Pengalokasian BTKL batako

Rp. $13.200 .000 \times 7.400 .000 / 106.207 .500=$ Rp. 8.873 .950

Perhitungan biaya tenaga kerja langsung Paving Block dan Batako UD. Mitra Utama mengalokasikan biaya tenaga kerja langsung sebagai berikut: 
Tabel 7. Pengalokasian biaya tenaga kerja langsung periode mei 2017

\begin{tabular}{ccc}
\hline Produk & \multicolumn{2}{c}{$\begin{array}{c}\text { biaya tenaga kerja } \\
\text { langsung }\end{array}$} \\
\hline Paving Block & $\mathrm{Rp}$ & $4,326,050$ \\
Batako & $\mathrm{Rp}$ & $8,873,950$ \\
\hline Jumlah & $\mathbf{R p}$ & $\mathbf{1 3 , 2 0 0 , 0 0 0}$ \\
\hline Sumber: Data primer diolah, 2017 &
\end{tabular}

\section{Biaya Overhead Pabrik}

Dibawah ini perhitungan biaya overhead pabrik dalam memproduksi batako dan paving block yang terdapat di UD. Mitra Utama :

Tabel 8. Perhitungan Biaya Overhead Pabrik Periode mei 2017

\begin{tabular}{ccc}
\hline Jenis & jumlah biaya \\
\hline biaya air & $\mathrm{Rp}$ & 125,000 \\
penyusutan alat cetak & $\mathrm{Rp}$ & 140,625 \\
Penyusutan gedung & $\mathrm{Rp}$ & 114,583 \\
\hline Jumlah & $\mathbf{R p}$ & $\mathbf{3 8 0 , 2 0 8}$ \\
\hline
\end{tabular}

Sumber: Data primer diolah, 2017

Dalam perhitungan biaya overhead pabrik baku Paving Block dan Batako UD. Mitra Utama membagi jumlah biaya bahan baku dengan unit yang diproduksi oleh masing-masing produk. Berikut perhitungan biaya overhead pabrik UD. Mitra Utama untuk masingmasing produk :

- $\quad$ Biaya overhead pabrik paving block

Tabel 9.Perhitungan Biaya Overhead Pabrik paving block Periode mei 2017

\begin{tabular}{ccc}
\hline Jenis & Jumlah Biaya \\
\hline Biaya Air & Rp & 81,250 \\
Penyusutan Alat Cetak & Rp & 91,406 \\
Penyusutan Gedung & Rp & 74,479 \\
\hline Jumlah & Rp & $\mathbf{2 4 7 , 1 3 5}$ \\
\hline Sumber : Data primer diolah, 2017 & &
\end{tabular}

- Biaya Overhead Pabrik Batako

Tabel 10. Perhitungan Biaya Overhead Pabrik Batako

\begin{tabular}{ccc} 
Periode mei 2017 & & \\
\hline Jenis & \multicolumn{3}{c}{ Jumlah Biaya } \\
\hline Biaya Air & $\mathrm{Rp}$ & 43,750 \\
Penyusutan Alat Cetak & $\mathrm{Rp}$ & 49,219 \\
Penyusutan Gedung & $\mathrm{Rp}$ & 40,104 \\
\hline Jumlah & Rp & $\mathbf{1 3 3 , 0 7 3}$ \\
\hline
\end{tabular}

Sumber : Data primer diolah, 2017

\section{Harga Pokok Produksi}

Setelah unsur-unsur biaya produksi dihitung baik biaya bahan baku, tenaga kerja langsung, dan biaya overhead pabrik, maka harga pokok produksi UD. Mitra Utama dapat ditentukan. Dalam menentukan harga pokok produksi UD. Mitra Utama dilakukan sebagai berikut :

- Metode Akuntansi Biaya Tradisional

Berikut perhitungan harga pokok produksi UD. Mitra Utama dengan menggunakan metode Akuntansi Biaya Tradisional

Harga Pokok Produksi paving block dengan menggunakan metode akuntansi biaya tradisional

\begin{tabular}{llr} 
Biaya Bahan Baku & Rp & $6,698,004$ \\
Biaya Tenaga Kerja Langsung & Rp & $4,326,050$ \\
Biaya Overhead Pabrik & Rp $\quad 247,135$ \\
\cline { 2 - 2 } Harga Pokok Produksi & Rp 11,271,190
\end{tabular}

Perhitungan di atas menunjukkan bahwa harga pokok produksi paving block UD. Mitra Utama dengan metode akuntansi biaya tradisional selama bulan Mei 2017 sebesar Rp. 11,271,190.

Untuk mendapatkan Harga Pokok Produksi per unit paving block UD. Mitra Utama dapat dilakukan dengan membagi total Harga Pokok Produksi Paving Block UD. Mitra Utama dengan jumlah unit produksi paving block, yaitu sebagai berikut :

Rp. 11,271,190 / 16.575 unit $=$ Rp. 680,01 per unit

Harga Pokok Produksi batako dengan menggunakan metode akuntansi biaya tradisional sebagai berikut :

$\begin{array}{llr}\text { Biaya Bahan Baku } & \text { Rp } & 13,739,496 \\ \text { Biaya Tenaga Kerja Langsung } & \text { Rp } & 8,873,950 \\ \text { Biaya Overhead Pabrik } & \text { Rp } & 133,073 \\ \text { Harga Pokok Produksi } & \text { Rp } & 22,746,518\end{array}$

Perhitungan diatas menunjukkan bahwa harga pokok produksi batako UD. Mitra Utama dengan metode Akuntansi biaya tradisional selama bulan Mei 2017 sebesar Rp.22,746,518.

Untuk mendapatkan Harga Pokok Produksi per unit Batako UD. Mitra Utama dapat dilakukan dengan membagi total Harga Pokok Produksi Batako UD. Mitra Utama dengan jumlah unit produksi Batako, yaitu sebagai berikut : 
Rp. $22,746,518 / 8.925$ unit $=$ Rp. $2.546,63$ per unit

\section{- Metode Activity Based Costing (ABC) System}

Activity-Based Costing System merupakan metode perbaikan dari Sistem Tradisional. Activity-Based Costing System ini merupakan metode perhitungan biaya yang dapat memberikan alokasi Biaya Overhead Pabrik yang lebih akurat dan relevan. Pada metode ini, seluruh Biaya Tidak Langsung dikelompokkan sesuai dengan aktivitas masing-masing.

Berikut perhitungan harga pokok produksi UD. Mitra Utama dengan menggunakan metode Activity Based Costing (ABC) System :

Tabel 11. Perhitungan Harga Pokok Produksi dengan Metode Acticity Based Costing (ABC) System Periode mei 2017

\begin{tabular}{lrrrr}
\hline & \multicolumn{2}{c}{ Paving Block } & \multicolumn{2}{c}{ Batako } \\
\hline Bahan Baku Langsung & $\mathrm{Rp}$ & $6,698,004$ & $\mathrm{Rp}$ & $13,739,496$ \\
Tenaga Kerja Langsung & $\mathrm{Rp}$ & $4,326,050$ & $\mathrm{Rp}$ & $8,873,950$ \\
$\begin{array}{l}\text { Overhead : } \\
\text { biaya air }\end{array}$ & $\mathrm{Rp}$ & 40,966 & $\mathrm{Rp}$ & 84,034 \\
$\begin{array}{l}\text { Penyusutan Alat } \\
\text { Cetak }\end{array}$ & $\mathrm{Rp}$ & 46,875 & $\mathrm{Rp}$ & 93,750 \\
$\begin{array}{l}\text { Penyusutan } \\
\text { gedung }\end{array}$ & $\mathrm{Rp}$ & 37,553 & $\mathrm{Rp}$ & 77,031 \\
$\begin{array}{l}\text { Total biaya } \\
\begin{array}{l}\text { Unit yang diproduksi } \\
\text { Biaya per unit }\end{array}\end{array}$ & $\mathrm{Rp}$ & $11,149,449$ & $\mathrm{Rp}$ & $22,868,260$ \\
\hline Sumber : Data primer diolah, & $\mathrm{Rp}$ & 672.6666 & $\mathrm{Rp}$ & $2,562.2700$ \\
\hline
\end{tabular}

Dari perhitungan pada tabel diatas yang membedakan perhitungan metode Activity Based Costing (ABC) System dengan metode Tradisional terletak pada perhitungan biaya Overhead Pabrik. Pada metode Activity Based Costing (ABC) System perhitungan biaya overhead pabrik dihitung berdasarkan aktifitas-aktifitas pada proses produksi.

E. Perbandingan Perhitungan Metode Perusahaan dengan Metode Activity Based Costing (ABC) System

Setelah melakukan perhitungan Harga Pokok Produksi dengan menggunakan metode perusahaan dan metode Activity Based Costing (ABC) System, maka akan didapatkan Harga Pokok Produksi yang berbeda. Berikut perbandingan Harga Pokok Produksi metode perusahaan dan metode Activity Based Costing (ABC) System:
Tabel 12. Perbandingan Harga Pokok Produksi Metode Perusahaan dengan Metode Acticity Based Costing $(A B C)$ System

\begin{tabular}{|c|c|c|c|c|}
\hline \multirow[b]{2}{*}{$\begin{array}{c}\text { Jenis } \\
\text { Produk }\end{array}$} & \multicolumn{2}{|c|}{ Harga Pokok Produksi } & \multirow{2}{*}{\multicolumn{2}{|c|}{ Selisih }} \\
\hline & $\begin{array}{l}\text { Metode } \\
\text { Perusahaan }\end{array}$ & $\begin{array}{l}\text { Metode Activity } \\
\text { Based Costing } \\
\text { (ABC) System }\end{array}$ & & \\
\hline Paving Block & Rp $11,271,190$ & Rp $11,149,449$ & $\mathrm{Rp}$ & 121,742 \\
\hline Batako & Rp $22,746,518$ & Rp 22,868,260 & $(\mathrm{Rp}$ & $121,742)$ \\
\hline
\end{tabular}

Berdasarkan hasil perhitungan di atas diketahui bahwa perbedaan perhitungan antara metode akuntansi biaya tradisional dengan metode Activity Based Costing $(A B C)$ System terletak pada pembebanan biaya overhead. Pada metode akuntansi biaya tradisional pengalokasian biaya overhead pabrik dilakukan berdasarkan unit yang diproduksi. Sedangkan pada metode Activity Based Costing (ABC) System pengalokasian biaya overhead pabrik dilakukan berdasarkan aktifitas yang dilakukan oleh setiap produk.

Perhitungan harga pokok produksi dengan menggunakan akuntansi biaya tradisional untuk produk paving block sebesar Rp 11,271,190, untuk produk batako sebesar Rp22,746,518. Harga pokok produksi dengan menggunakan metode Activity Based Costing (ABC) System untuk produk paving block sebesar Rp11,149,449, untuk batako sebesar Rp22,868,260. Pada produk paving block mengalami overcosting atau pembebanan biaya terlalu tinggi, sedangkan pada produk batako mengalami undercosting atau pembebanan biaya terlalu rendah.

\section{Kesimpulan}

Berdasarkan hasil penelitian yang telah dilakukan mengenai penetapan harga pokok produksi menggunakan metode Activity Based Costing (ABC) System pada UD. Mitra Utama dapat disimpulkan bahwa:

1. Penentuan harga pokok produksi yang dilakukan oleh UD. Mitra Utama dengan menggunakan metode akuntansi biaya tradisional mengakibatkan terjadinya distorsi biaya dalam menetapkan harga pokok produksi. Dampak yang terjadi adalah terjadinya pembebanan biaya yang terlalu rendah (undercosting) atau terjadinya pembebanan biaya yang terlalu tinggu (overcosting).

2. Perhitungan harga pokok produksi dengan menggunakan metode akuntansi biaya tradisional menghasilkan harga pokok produksi untuk paving block sebesar Rp 11,271,190, untuk batako sebesar Rp 22,746,518.

3. Perhitungan harga pokok produksi dengan menggunakan metode Activity Based Costing 
(ABC) System menghasilkan harga pokok produksi untuk paving block sebesar Rp11,149,449, dan untuk batako sebesar Rp22,868,260.

4. Terdapat perbedaan hasil perhitungan harga pokok produksi antara metode akuntansi biaya tradisional dengan metode Activity Based Costing (ABC) System. Perbedaan tersebut mengakibatkan produk paving block mengalami overcosting atau pembebanan biaya terlalu tinggi, sedangkan produk batako mengalami undercosting atau pembebanan biaya terlalu rendah.

\section{Saran}

Adapun saran yang diberikan kepada UD. Mitra Utama adalah sebagai berikut :

1. Sebaiknya UD. Mitra Utama meninjau kembali sistem perhitungan harga pokok produksi dengan menggunakan metode akuntansi biaya tradisional, dikarenakan masih terdapat overcosting dan undercosting didalamnya.

2. UD. Mitra Utama hendaknya mempertimbangkan untuk menerapkan metode Activity Based Costing $(A B C)$ System dalam melakukan perhitungan harga pokok produksi.

\section{Daftar Pustaka}

Carter, William K. 2009. Akuntansi Biaya, Buku I, Edisi 14, Salemba Empat, Jakarta.

Blocher, Edward J., David E.Stout, dan Gary Cokins. 2011. Manajemen biaya dengan Penekanan
Strategis. Buku I. Edisi kelima. Diterjemahkan oleh David Wijaya Jakarta : Salemba Empat

Ilham. 2013. Penentuan Harga Pokok Produksi Percetakan Sablon Otakkan Production di Yogyakarta.

Erawati. 2012. Analisis Harga Pokok Produksi Sebagai Dasar Penetuan Harga Jual Pada CV Harapan Inti Usaha Palembang

Prastiti, Ayu Esa D., Saifi, M., Z.A, Zahro. 2016. Analisis Penentuan Harga Pokok Produksi Dengan Metode Activity Based Costing System (Sistem ABC).Jurnal Administrasi Bisnis (JAB). Vol. 39. Halaman 16-24

Lasena, Sitty R. 2013. Analisis Penentuan Harga Pokok Produksi Pada PT. Dimembe Nyiur Agripro. Jurnal EMBA. Vol. 1. Halaman 585-592

Batubara, Helmina. 2013. Penentuan Harga Pokok Produksi Berdasarkan Metode Full Costing Pada Pembuatan Etalase Kaca dan Alumunium Di UD. Istana Alumunium Manado. Jurnal EMBA. Vol. 1. Halaman 217-224

Rotikan, Gloria S. 2013. Penerapan Metode Activity Based Costing Dalam Penentuan Harga Pokok Produksi Pada PT. Tropica Cocoprima. Jurnal EMBA. Vol.1. Halaman 1019-1029

Setiadi, P., Saerang, David P.E., Runtu, T. 2014. Perhitungan Harga Pokok Produksi Dalam Penentuan Harga Jual Pada CV. Minahasa Mantap Perkasa. Jurnal Berkala Ilmiah Efisiensi. Vol. 14. Halaman 70-82 